\title{
Analysis of the composition of trail pheromone secreted from live Camponotus japonicus by HS-SPME GC/MS (HeadSpace-Solid Phase MicroExtraction Gas Chromatography/Mass Spectrometry)
}

\author{
Kyung-Eun Park, Dong-Kyu Lee, Sung Won Kwon and Mi-Young Lee ${ }^{1, \star}$ \\ College of Pharmacy, Seoul National University, Korea \\ ${ }^{1}$ Occupational Safety and Health Research Institute, Korea Occupational Safety and Health Agency, Korea \\ (Received June 25, 2012; Revised August 22, 2012; Accepted August 22, 2012)
}

\section{HS-SPME GC/MS법을 이용한 일본왕개미의 trail pheromone 성분 분석}

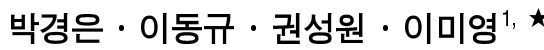

서울대학교 약학대학, ${ }^{1}$ 한국산업안전보건공단 산업안전보건연구원

(2012. 6. 25. 접수, 2012. 8. 22. 수정, 2012. 8. 22. 승인)

\begin{abstract}
GC/MS has been utilized for many applications due to great resolution and reproducibility, which made it possible to build up the database of mass spectrum, while HS-SPME has the advantage of solventfree extraction of volatile compounds. The combination of these two methods, HS-SPME GC/MS, enabled many scientific applications with various possibilities. In this study, the analysis of trail pheromone excreted from live Camponotus japonicus with the feature of solvent-free extraction was carried out and the optimization for this analysis was performed. The major compounds detected were $\mathrm{n}$-decane, $\mathrm{n}$-undecane, and $\mathrm{n}$-tridecane. Optimization for the best detection of these hydrocarbons was processed in the point of SPME parameter (selection of fiber, extraction temperature, extraction time, etc.). The advantage of the analysis of live sample is to analyze phenomenon right after it is excreted by ants. But the experimental process has restriction of extraction temperature and time because of the analysis of live ants. Establishing the process of HS-SPME GC/MS applied to live samples shown in this study can be a breakthrough for the ecofriendly and ethical research of live things.

요 약: GC/MS (gas chromatography/mass spectrometry)는 훌륭한 분리능과 재현성으로 인해 널리 활용 되고 있으며, 정립된 데이터베이스의 활용을 통한 성분 분석에서 활용도가 높다. 또한 HS-SPME (headspacesolid phase micro extraction)법은 용매로 추출을 하지 않은 휘발성 물질의 추출을 하는데 널리 사용되었 다. 이 두 방법의 연계는 다양한 시료에서 발생하는 휘발성 성분의 분석에 널리 활용되었다. 위 특징을 이용하여 살아있는 Camponotus japonicus가 분비하는 미량의 페로몬 구성 성분의 분석 방법을 확립하였 다. n-Decane, n-undecane, n-tridecane 등의 물질이 미량 페로몬에서 검출되었으며, 이 탄화수소들을 분석
\end{abstract}

^ Corresponding author

Phone : +82-(0)32-510-0825 Fax : +82-(0)32-510-0862

E-mail : cookmom@kosha.net 
하는데 적합한 SPME fiber, 추출 온도, 추출 시간을 최적화하였다. 살아있는 시료를 분석할 수 있기 때 문에 특정 현상이 발생하는 그 순간을 분석하는 장점이 있는 한편, 살아있는 시료를 분석하기 때문에 추 출 시간 등이 제한된다는 한계점이 있었으나 살아있는 HS-SPME GC/MS 분석방법이 정립된다면 살아 있는 시료를 죽일 필요 없다는 점에서 친환경적인 연구의 발전에 해결책이 될 수 있을 것으로 전망한다.

Key words: HS-SPME GC/MS, volatile organic compound, trail pheromone, live Camponotus japonicus

\section{1. 서 론}

GC/MS (Gas chromatography/mass spectrometry)는 훌륭한 분리능과 재현성으로 인하여 여러 휘발성 물 질의 분석, 또는 유도체화를 통한 비휘발성 물질의 분석에 널리 쓰이고 있다. ${ }^{1}$ 특히 재현성 있는 질량 스펙트럼으로 인해 정립된 데이터베이스의 활용을 통한 물질의 규명이 가능하다는 점에서 활용도가 높 다. ${ }^{2}$ 이중에서도 HS-SPME (Head Space-Solid Phase MicroExtraction) 법과 연계된 $\mathrm{GC} / \mathrm{MS}$ 는 유기용매를 사용하지 않으며, 간편한 추출방법으로 인하여 많은 연구가 진행되고 있다. 구체적으로, 흔히 접할 수 있는 공기, 음식 내 VOC (Volatile organic compound)의 분석 부터 3.4 질병의 진단에 필요한 소변 또는 혈액에서의 $\mathrm{VOC}$ 의 분석까지 다양한 분야에서 연구되고 있다. ${ }^{5,6}$

SPME 방법 중에서도 HS-SPME 법만의 장점은 시 료에 직접 닿지 않아도 분석이 가능하다는 점이다. 이 러한 특징으로 인하여 살아있는 시료에서 직접 분비 되는 $\mathrm{VOC}$ 의 분석이 가능하게 되었으며, 이는 살아 있는 생물, 더 작은 단위로는 세포의 생존 중 나타나 는 여러 현상에 대한 연구를 수월하게 만들었다. 구체 적으로, 살아있는 세포에서 분비되는 $\mathrm{VOC},{ }^{7} \mathrm{fungi},{ }^{8}$ 살아 있는 나뭇잎의 분비물 분석 ${ }^{9}$ 등에 대한 논문이 있으며, 곤충들이 사용하는 semiochemical(화학물질을 통한 같은 군집간의 의사소통 방식 $)^{10}$ 에 대한 연구에 접목되었다. 살아 있는 시료에 대한 HS-SPME 법은 다양한 장점을 가지고 있다. 첫째로, 시료를 손실시키 지 않고 다시 활용할 수 있으며, 시료가 살아있는 동 안에만 발견할 수 있는 현상에 대한 연구를 진행할 수 있다는 장점을 갖고 있다. 둘째로, 유기용매를 전 혀 사용하지 않기 때문에 연구 진행의 안정성과 환경 친화적인 연구가 가능하다는 장점을 갖고 있다. 따라 서 연구원들의 건강에 해를 끼치지 않는 연구가 다양 하게 진행되고 있다.

Camponotus japonicus는 한국과 일본에서 흔하게 발견할 수 있는 개미로서11 아직 연구가 많이 진행되
지 않은 상황이다. Semiochemical 중 Camponotus 속 에게서 관찰되는 페로몬의 정성분석은 현재 연구되어 있으나, 살아있는 개미가 직접 분비하는 페로몬이 아 닌 페로몬의 저장고인 dufuor gland를 적출하여 유기 용매로 추출하여 분석하였기 때문에 ${ }^{12-14}$ 이는 분비물 이 아니고, 분비 직전의 페로몬에 대한 연구일 뿐이 다(Fig. 1). 따라서 개미의 의사소통에 대한 연구에는 적합하지 않다. 이 논문에서는 살아있는 생물의 분비물 에 대해 분석이 가능한 HS-SPME GC/MS를 이용하여 개미가 분비하는 페로몬에 대한 연구를 진행하였다. 이 실험에서 사용하는 C. japonicus의 dufuor gland에서 발 견된 성분에는 Covats index의 지표물질로 쓰이는 nundecane, n-tridecane과 ${ }^{15}$ 구조가 유사한 물질인 ndecane을 주성분으로 하며, 그 외에도 5-methylundecane, 3-methylundecane, n-dodecane, dodecanol, npentadecane 등의 성분을 포함하고 있다(Fig. 2). ${ }^{12}$ 그 러나 이는 dufuor gland에서 발견된 것이며, 분비된 페로몬에서의 성분은 아직 확인되지 않았다. 따라서 본 연구에서는 HS-SPME GC/MS를 이용하여 분비된 페로몬의 구성성분에 대해서 밝히고자 한다.

\section{2. 실 험}

\section{1. 시료 및 기구}

Decane ( $\geq 99.8 \%$, analytical grade)과 tridecane ( $\geq 99.5 \%$, analytical grade), 그리고 먹이로 사용된 sucrose (reagent grade)는 Sigma-Aldrich (St. Louis, MO, USA)에서 구 매하였다. Undecane ( $\geq 99.5 \%$, analytical grade)는 Tokyo Chemical Industry (Kita-ku, Tokyo, Japan)에서 구매하 였다. 표준품 희석액을 만들 때 사용된 acetone (HPLC grade)은 J.T. Baker (NJ, USA)에서, Water (HPLC grade) 는 덕산약품(경기도, 한국)에서 구매하였다. GC/MS 시료를 담는 screw-top $20 \mathrm{~mL}$ 바이알 capped with PTFE/silicone septa는 Agilent Technologies에서 구매 하여 사용하였다.

GC-MS는 Agilent 7890A GC system과 연동된 5975C 


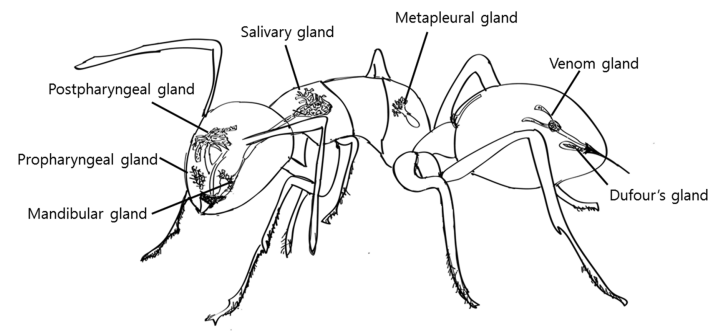

Fig. 1. Anatomy of endocrine systems of ant.

$$
\begin{aligned}
& \begin{array}{ccc}
\mathrm{Me}-\left(\mathrm{CH}_{2}\right)_{8}-\mathrm{Me} & \mathrm{Me}-\left(\mathrm{CH}_{2}\right)_{9}-\mathrm{Me} & \mathrm{Me}-\left(\mathrm{CH}_{2}\right)_{11}-\mathrm{Me} \\
\mathrm{n} \text {-decane } & \mathrm{n} \text {-undecane } & \mathrm{n} \text {-tridecane }
\end{array} \\
& \underset{\mathrm{n}-\mathrm{Bu}-\mathrm{CH}_{5}-\left(\mathrm{CH}_{2}\right)_{5}-\mathrm{Me}}{\mathrm{Me}} \underset{\mathrm{Et}-\mathrm{CH}-\left(\mathrm{CH}_{2}\right)_{7}-\mathrm{Me}}{\text { 3-methylundecane }} \\
& \mathrm{Me}-\left(\mathrm{CH}_{2}\right)_{10}-\mathrm{Me} \mathrm{Me}-\left(\mathrm{CH}_{2}\right)_{10}-\mathrm{Me} \mathrm{Me}-\left(\mathrm{CH}_{2}\right)_{13}-\mathrm{Me} \\
& \text { n-dodecane } \\
& \text { pentadecane } \\
& \mathrm{D} 1-\mathrm{OH} \\
& \text { dodecanol }
\end{aligned}
$$

Fig. 2. Type and structure of pheromone (referred to substance identifier by "Scifinder").

triple axis detector를 장착한 inert XL mass spectrometer (Agilent technologies, DE, USA)를 사용하였다. 구체 적인 $\mathrm{GC} / \mathrm{MS}$ 의 조건은 Table 1 에 기록하였다. Solid phase-micro extraction은 GERSTELs Solid Phase Micro Extraction (GERSTEL Inc., 701 Digital drive, Suite J Linthicum, MD 21090, USA)를 사용하였다. 또한 SPME fiber polyacrylate (PA) $85 \mu \mathrm{m}$, polydimethylsiloxane (PDMS) $100 \mu \mathrm{m}$, carboxen/polydimethylsiloxane (CAR/ PDMS) $75 \mu \mathrm{m}$, polydimethylsiloxane/divinylbenzene
(PDMS/DVB) $65 \mu \mathrm{m}$, divinylbenzene/carboxen/polydimethylsiloxane (DVB/CAR/PDMS) 모두 Supelco (trademarks of Sigma-Aldrich, St. Louis, MO, USA)에서 구매하였다.

$\mathrm{GC} / \mathrm{MS}$ 자료의 수집과 처리에 Chemstation (Agilent technologies, DE, USA) 를 사용하였고, 또한 데이터를 통한 정량 및 mass spectrum의 확인에는 DataAnalysis 4.0 (Bruker daltonik $\mathrm{GmbH}$, Bremen, Germany)을 사 용하였다.

\section{2. 실험방법}

\subsection{1. 개미 시료 전처리}

개미의 학명은 Camponotus japonicus 이며 이는 Biobiba Ant Kingdom(대구, 한국)에서 구매하였다. 개 미를 바이알에 담았을 경우 바이알에 잔존하고 있는 휘발성 유기화합물을 제거하여 개미의 생존율을 높이 기 위해서 압축공기발생기(OF302-25MD2, JUN-AIR, Benton harbor, MI, USA)를 이용하여 실제 공기와 유 사한 상태를 만들어 주었다. 무게 범위 $60 \mathrm{mg}-80 \mathrm{mg}$ 의 개미를 포획하여 개미 개체군간의 차이를 최소화 하였다. 또한 땅 속에서 안정감을 갖는 개미들을 위해 바이알에 알루미늄 호일(롯데알미늄(주), 경기도, 한국) 를 감싸 암실로 만들어 주었다. 또한 개미가 군집하여 있을 때의 영향을 최소화 하기 위하여 실험하고자 하 는 개미는 1 시간 전에 미리 포획하여 바이알에 한 마리씩 독립시켜 놓았다.

\subsubsection{SPME 조건의 최적화}

최적화에 앞서 개미의 페로몬 분비를 유도한 뒤 $\mathrm{HS}-\mathrm{SPME} \mathrm{GC/MS}$ 로 검출한 뒤 $\mathrm{GC} / \mathrm{MS}$ 에서 성분의 규명에 쓰이는 NIST database를 활용하여 target 물질

Table 1. Analytical condition by GC/MS

\begin{tabular}{ll}
\hline \hline & \multicolumn{1}{c}{ Gas chromatography } \\
\hline Column & ZB- $624,60 \mathrm{~m} \times 0.25 \mathrm{~mm}, 1.40 \mu \mathrm{m}($ Phenomenex, zebron, USA) \\
Carrier gas & Helium gas at constant rate flow $1.0 \mathrm{~mL} / \mathrm{min}$ \\
Inlet mode & Splitless, split mode $(50: 1)$ at $0.5 \mathrm{~min}$ after injection \\
Oven temperature program & $35{ }^{\circ} \mathrm{C}$ for $10 \mathrm{~min}-5{ }^{\circ} \mathrm{C} / \mathrm{min}$ to $240{ }^{\circ} \mathrm{C}-240{ }^{\circ} \mathrm{C}$ for $5 \mathrm{~min}$ \\
Inlet temperature & $250{ }^{\circ} \mathrm{C}$ \\
\hline & \multicolumn{1}{c}{$\mathrm{MS}$ Detector } \\
\hline Mass range & $25{ }^{\circ} \mathrm{C} 190 \mathrm{~m} / \mathrm{z}$ \\
Ionization energy & $70 \mathrm{eV}$ \\
Ion source temperature & $250{ }^{\circ} \mathrm{C}$ \\
Transfer line temperature & $250{ }^{\circ} \mathrm{C}$ \\
Scan rate & $3.06 \mathrm{scan} / \mathrm{sec}$ \\
\hline
\end{tabular}


을 정하였다. ${ }^{2}$ 이를 통해 확인한 결과 분비된 페로몬 에서는 n-decane, n-undecane, n-tridecane 만이 검출됨 을 확인하였고, 따라서 세 가지의 성분에 대하여 최적 화를 수행하였다.

첫 번째로 5 가지 종류의 coated fiber중 우리 실험 target 물질의 검출에 가장 적합한 fiber를 찾기 위해 $10 \mathrm{mg} / \mathrm{L}$ 까지는 아세톤으로 희석하고 다음 단계부터는 HPLC grade water로 희석한 $400 \mu \mathrm{g} / \mathrm{L}$ 혼합 용액 (decane, undecane, tridecane, C. japonicus 페로몬 주성 분 3 가지) 을 분석하여 각 fiber 별로 흡착비율을 확인 하였다. 5 가지 fiber는 각각 polyacrylate (PA) $85 \mu \mathrm{m}$, polydimethylsiloxane (PDMS) $100 \mu \mathrm{m}$, carboxen/polydimethylsiloxane (CAR/PDMS) $75 \mu \mathrm{m}$, polydimethylsiloxane/divinylbenzene (PDMS/DVB) $65 \mu \mathrm{m}$, divinylbenzene/carboxen/polydimethylsiloxane (DVB/CAR/PDMS) $50 / 30 \mu \mathrm{m}$ 이다. Fiber의 종류 외의 다른 변수들인 추출 시간은 30 분, 온도는 $25{ }^{\circ} \mathrm{C}$, 탈착 시간은 10 분으로 일정하게 맞추었다.

두 번째로 추출 시간과 온도에 대해서 최적값을 설 정하였다. 위와 동일한 혼합물을 사용하여 각각 15 , 30 분, $1,2,3,4,5$ 시간으로 추출 시간을 설정한 뒤 가장 적합한 값을 정하였다. 추출 시간 설정 시 $\mathrm{PDMS} / \mathrm{DVB}$ fiber를 사용하였고 온도는 $25^{\circ} \mathrm{C}$, 탈착 시간은 10 분으로 일정하게 맞추었다. 추출 온도는 일 반적으로 $80{ }^{\circ} \mathrm{C}$ 정도로 하여 휘발성 물질을 쉽게 검 출하도록 설정하나, 살아있는 시료에 사용하는 우리 실험에 맞추어 $25^{\circ} \mathrm{C}$ 의 상온으로 설정하였다.

세 번째로 탈착 시간을 설정하였다. 위와 마찬가지 방법으로 하여 $1,5,10,20,30$ 분으로 추출 시간을 설정한 뒤 가장 적합한 값을 정하였다. 이 때 fiber는 $\mathrm{PDMS} / \mathrm{DVB}$ 를 사용하였고 추출 시간은 30 분, 온도는 25 로 일정하게 하였다.

\subsection{3. $\mathrm{GC} / \mathrm{MS}$ 의 검증}

첫째로, 위에서 최적화된 $\mathrm{SPME}$ 법과 $\mathrm{GC} / \mathrm{MS}$ 조건 을 사용하여 $50,25,12.5,5,2.5,1.25,0.5 \mu \mathrm{g} / \mathrm{L}$ 의 표 준물질 혼합용액(주성분인 n-decane, n-undecane, ntridecane의 혼합물)을 측정하고 직선성과 검출한계, 정량한계를 확인하였다. 또한 $50 \mu \mathrm{g} / \mathrm{L}$ 의 혼합 용액을 사용하여 질량 분석의 정밀도를 확인하였다.

\subsection{4. 개미의 자극을 통한 페로몬의 분비 유도}

C. japonicus worker 한 마리를 포획한 뒤 screwtype GC 바이알에 넣고 HS-SPME GC/MS로 상온에
서 추출하여 분석하였으나, 이 때 분비된 페로몬의 양 이 극미량이라서 검출되지 않았다. 살아있는 상태에서 개미가 방출하는 페로몬의 농도를 높여 정량 가능한 범위로 만들기 위해 한 개의 바이알에 포획한 개미 3 마리를 넣고 실험을 진행하였다. 또한 페로몬의 분비 를 유도하기 위한 자극으로 먹이를 사용하였다. ${ }^{16}$ 먹 이로는 $1 \mathrm{M}$ sucrose를 사용하였으며 $10 \mu \mathrm{L}$ 를 넣은 바이알에 개미를 넣고 10 분간 방치한 후 새로운 바 이알에 개미를 옮긴 뒤 분비된 페로몬을 HS-SPME $\mathrm{GC} / \mathrm{MS}$ 법으로 분석하였다.

\section{3. 결 과}

\subsection{SPME 조건의 최적화}

실제 살아있는 개미의 페로몬을 분석하기 전에 세 가지의 페로몬 표준물질(n-decane, n-undecane, ntridecane)에 대해 추출 조건을 최적화하는 실험을 하

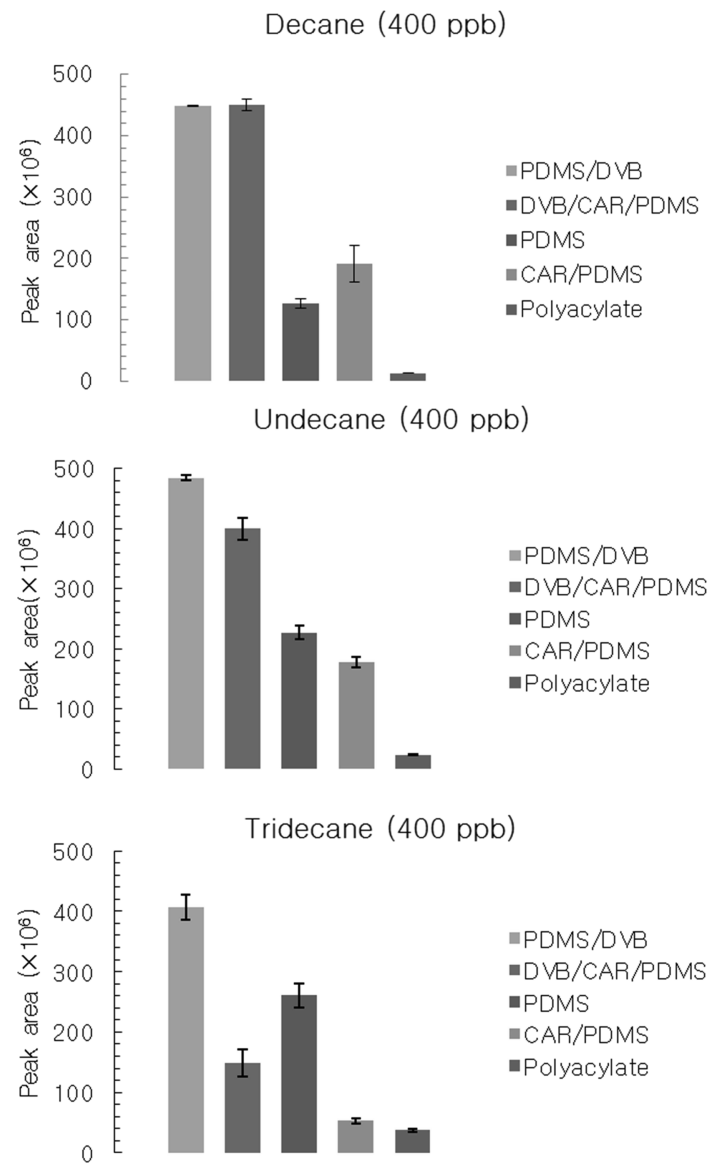

Fig. 3. Optimization of SPME fiber. 

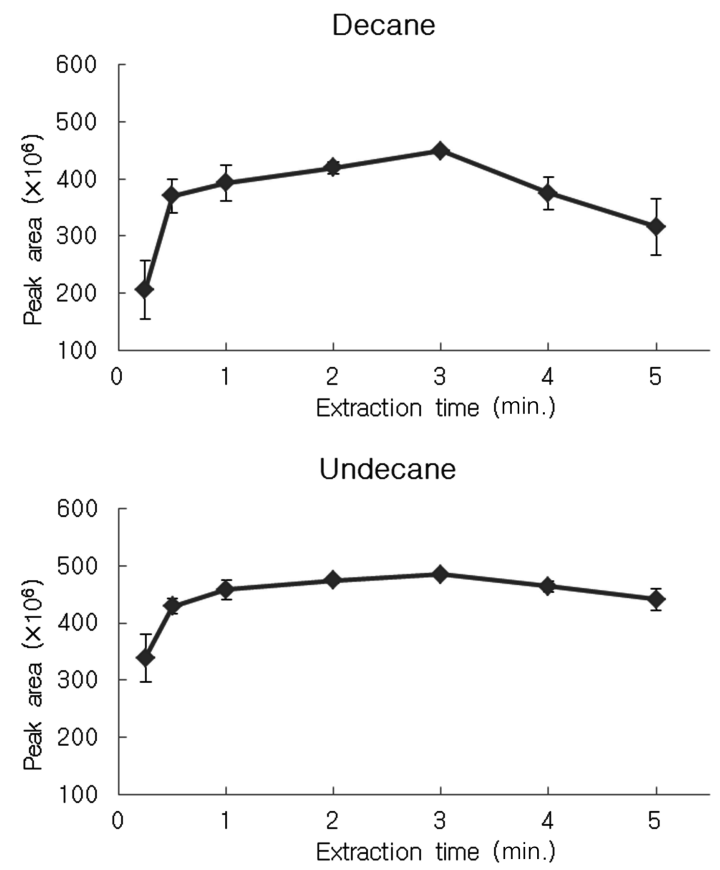

Tridecane

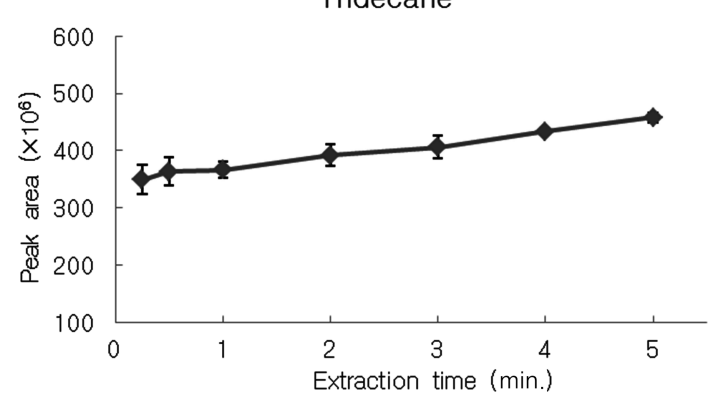

Fig. 4. Optimization of extraction time.

였다. SPME fiber의 종류(Fig. 3), 추출 시간(Fig. 4), 탈착 시간(Fig. 5)에 대해 최적화를 실시하였다.

n-Decane, n-undecane, n-tridecane 세 가지 물질 모 두 $65 \mu \mathrm{m} \mathrm{PDMS} / \mathrm{DVB}$ 가 다른 fiber에 비해 흡착량 과 정밀도가 월등히 높게 나타났다. 피크 면적으로 흡 착비율을 평가해 볼 때 $\mathrm{n}$-undecane에 대한 $50 / 30 \mu \mathrm{m}$ DVB/CAR/PDMS, $100 \mu \mathrm{m}$ PDMS, $75 \mu \mathrm{m}$ CAR/PDMS, $85 \mu \mathrm{m}$ polyacrylate의 흡착비율은 $65 \mu \mathrm{m}$ PDMS/DVB 에 비해 각각 $82,47,37,5 \%$ 로 떨어졌다.

추출 시간의 경우 n-decane과 n-undecane은 3 시간 으로 하였을 때 피크 면적이 가장 넓었고 n-tridecane 은 extraction time이 증가할수록 추출효율이 증가하였 다. 3 시간을 최적화된 추출 시간으로 해서 실제 살아 있는 개미를 대상으로 예비 실험 결과 밀폐된 바이알

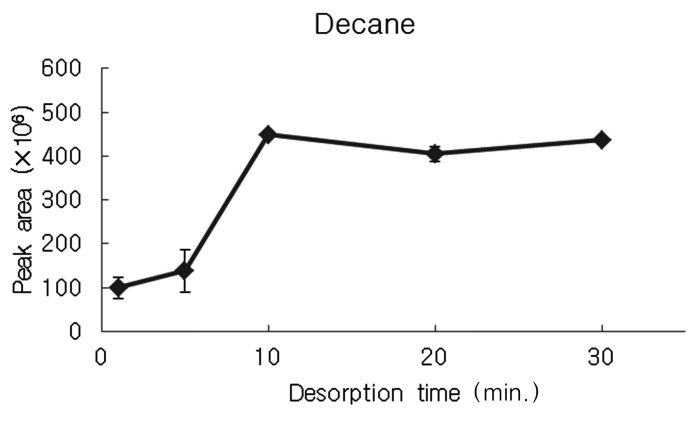

Undecane

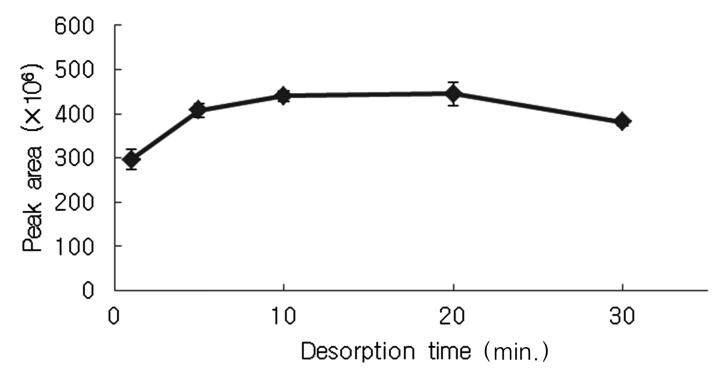

Tridecane

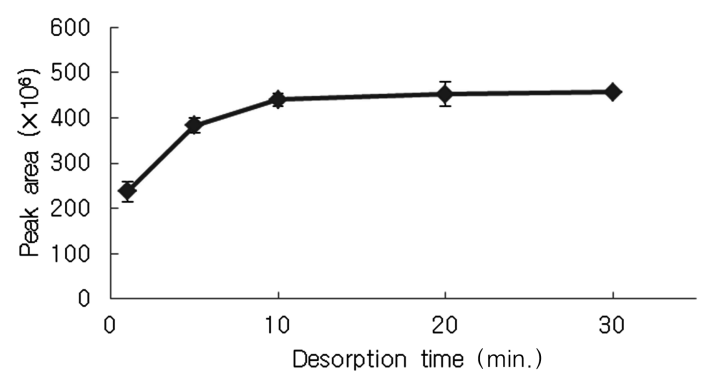

Fig. 5. Optimization of desorption time.

안에 개미가 3 시간 이상 오래 방치 될 경우 죽거나 비활동적으로 변하는 경우가 많았다. 따라서 살아있는 시료를 대상으로 하는 본 실험의 특성상 최대 추출 효율보다 추출하는 동안 개미를 생존시켜 다수의 개 미를 실험하는 조건에 초점을 맞춰 시료 추출 시간을 30 분으로 줄여서 실시하였다.

탈착 시간은 1,5 분에서 증가하여 10 분 이후에서 비교적 일정한 피크면적이 나타나고 재현성도 우수했 다. 본 실험에서 탈착 시간은 10 분으로 하였다.

\section{2. $\mathrm{GC} / \mathrm{MS}$ 법의 검증}

각 성분의 검출 한계와 정량 한계를 확인하였다. 검 출한계는 $\mathrm{S} / \mathrm{N}$ ratio (Signal to noise ratio) $=3$ 을 기준으 로 하였으며, 정량한계는 $\mathrm{S} / \mathrm{N}$ ratio $=10$ 을 기준으로 하 
Table 2. Calibration of 3 target compounds

\begin{tabular}{lcccc}
\hline \hline Compound & $\begin{array}{c}\text { Retention } \\
\text { time }(\min .)\end{array}$ & $\begin{array}{c}\text { Concentration range } \\
(\mu \mathrm{g} / \mathrm{L})\end{array}$ & Regression eqn. & $\begin{array}{c}\text { Correlation coefficient } \\
\left(\mathrm{r}^{2}\right)\end{array}$ \\
\hline n-Decane & 34.6 & $1.25-50$ & $\mathrm{y}=783,950 \mathrm{x}-10,318,342$ & 0.995 \\
n-Undecane & 38.2 & $0.5-50$ & $\mathrm{y}=2,930,646 \mathrm{x}-37,392,683$ & 0.995 \\
n-Tridecane & 44.4 & $0.5-50$ & $\mathrm{y}=1,711,496 \mathrm{x}-15,858,563$ & 0.997 \\
\hline
\end{tabular}
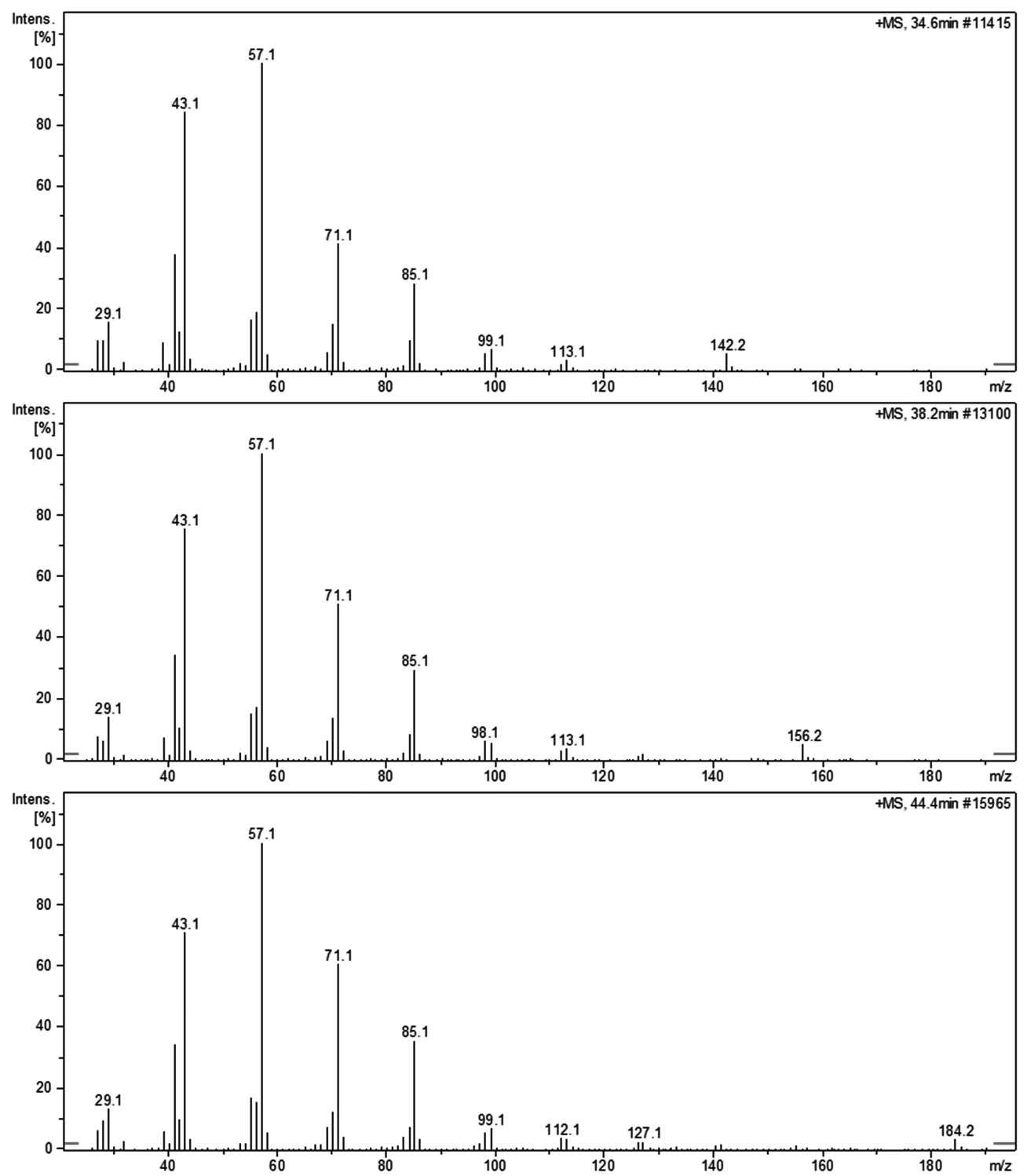

Fig. 6. Mass spectrum of n-decane, n-undecane, n-tridecane (top-down in sequence, $[\mathrm{M}]+$ of each compound : 142, 156, 184)

였다. n-Decane, n-undecane, n-tridecane의 검출한계는 순서대로 $0.25,0.05,0.13 \mu \mathrm{g} / \mathrm{L}$ 였으며, 정량한계의 경우 $0.5,0.25,0.5 \mu \mathrm{g} / \mathrm{L}$ 였다. 구체적인 직선성 시험과 검량
선의 확인 결과를 Table 2에 제시하였다. 또한 질량 스 펙트럼의 확인을 통해서 질량 정밀도를 확인하여, $\mathrm{n}$ decane, n-undecane, n-tridecane의 $[\mathrm{M}]^{+}$가 각각 142,156 , 


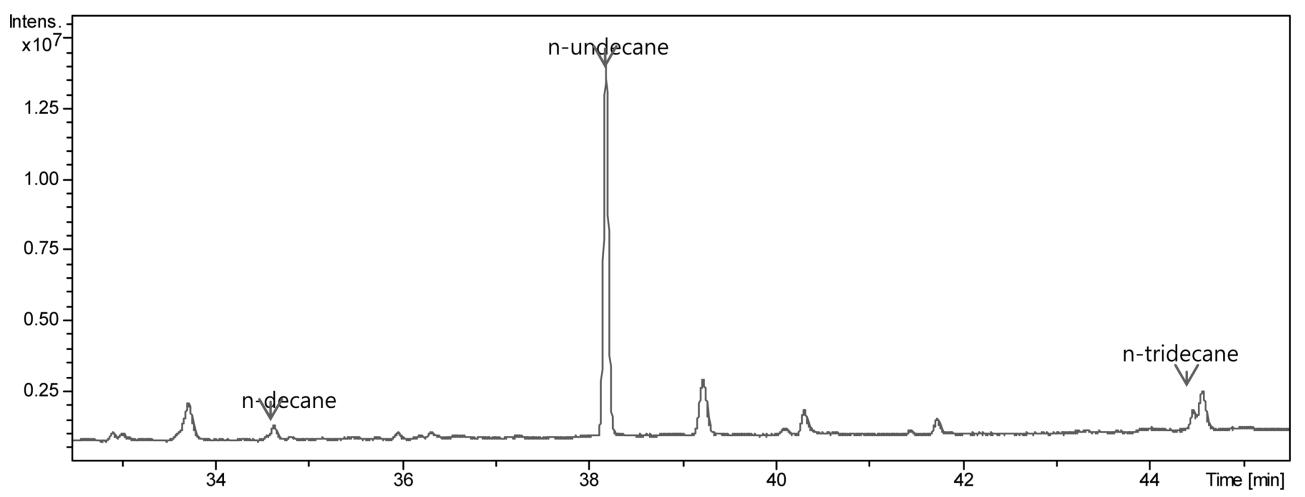

Fig. 7. Chromatogram of pheromone after stimulation with food.

Table 3. Quantitation of pheromone excreted by ants $(\mathrm{n}=20)$

\begin{tabular}{lcc}
\hline \hline Compound & Mean $(\mathrm{mg} / \mathrm{L})^{\mathrm{a}}$ & $\mathrm{SD}$ \\
\hline n-Decane & 0.016 & 0.015 \\
n-Undecane & 0.019 & 0.018 \\
n-Tridecane & 0.010 & 0.010 \\
\hline
\end{tabular}

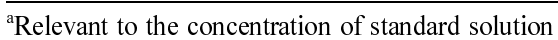

184로 계속 동일하게 나타남을 확인하였다(Fig. 6).

\section{3. 자극에 의해 분비된 개미 페로몬의 검출}

먹이 자극을 가한 후 검출된 페로몬의 3 가지 성분 을 크로마토그램을 바탕으로 하여 피크 넓이로 각각 정량하였다(n=20)(Fig. 7). n-Decane, n-undecane, ntridecane 각각 약 $0.016,0.019,0.010 \mathrm{mg} / \mathrm{L}$ 의 표준용 액과 농도가 상응하였다(Table 3). n-undecane이 가장 높은 농도로 검출 되었으며 n-tridecane은 검출되지 않 은 개체의 수가 2 로 가장 많았다. n-Decane, n-undecane 의 경우 검출되지 않은 개체는 없었다. 개미가 분비하 는 페로몬의 표준 편차가 n-decane, n-undecane, ntridecane 각각 약 $0.015,0.018,0.009$ 로 재현성이 뛰 어나게 좋다고는 할 수 없었으나, 자극을 가했을 경우 모든 개체에서 이들 성분이 검출되었다는 점은 확인 할 수 있었다.

\section{4. 고 찰}

SPME fiber는 coating 물질의 극성 정도와 두께에 따라 시료 중 추출되는 물질의 종류와 양이 결정되기 때문에 어떤 물질을 검출하고자 하는지에 따라 최적 화가 필요하다. 이 원리는 분석대상물질 fiber coating 물질-시료 matrix 사이의 분배계수의 차이에 기인한다.
SPME의 추출 능력은 시료의 headspace가 평형 상태 일 때 가장 높으며 코팅 두께가 두꺼울 수록 시료 흡 착 시간이 더 오래 걸리고 분석 효율이 떨어진다. 본 실험에서는 탄화수소류 물질을 목적성분으로 했으며 탄화수소를 HS-SPME로 추출할 경우에는 PDMS/ DVB fiber가 가장 추출 효율이 좋은 것으로 나타났다. HS-SPME에 있어 또 한 가지 중요한 점은 시료 전처 리 과정에서 용매를 거의 쓸 필요가 없지만 표준품을 희석할 때 쓰는 희석용매가 목적성분보다 휘발성이 크면서 해당 fiber에 흡착이 잘될 경우 목적성분의 검 출을 크게 방해하게 된다. 따라서 우리는 물에 잘 녹 지 않는 탄화수소류를 우선 아세톤으로 $10 \mathrm{mg} / \mathrm{L}$ 까지 희석시킨 후 그 뒤 농도는 모두 물로 희석하여 제조 함으로써 재현성과 민감성을 높였다.

현상이 일어나는 그 순간을 관찰한다는 의미에서, 본 실험에서 최적화한 HS-SPME GC/MS 분석방법은 현상 전후에 있을 수 있는 미지의 변수를 배제하는 좋은 방법이다. 그러나 현상 그 자체의 관찰에는 적합 하나, 다만 그 현상을 보여주는 비휘발성 화합물은 검 출하지 못한다는 한계점이 있다. 한마디로 $\mathrm{VOC}$ 만을 관찰할 수 있기에 target 물질의 다양성은 떨어지는 편 이다. 따라서 독성이 없고, 기화 상태에서 유도체화 할 수 있는 물질이 개발된다면 그 현상을 연구케 해 주는 물질을 발견하는데 있어 더욱 다양한 target을 바 탕으로 살아있는 생물에 대한 연구가 더욱 수월해질 것이다.

또한 이 논문에서 초점으로 두었던 살아있는 시료 의 분석이라는 점은 최적화 과정에서 몇 가지 제한이 있음을 확인했다. 실험에서 검출하고자 하는 물질을 분비하는 개미를 살려야 한다는 점 때문에 온도를 상 온에 가깝게 두어야 하기 때문에 추출 온도를 높이지 
못하며, 시료가 밀폐된 공간에서 계속 살아있어야 한 다는 제한으로 인해서 추출 시간을 너무 길게 할 수 도 없었다. 낮은 온도와 짧은 추출 시간으로 인해 추 출 효율이 낮은 편이기 때문에 각 시료에 해당하는 적합한 조건을 찾는 것이 반드시 수반되어야 한다. 또 한 살아있는 생물이 직접 분비하는 것이기 때문에 분 비량의 재현성을 획득하기는 쉽지 않으므로 이에 대 한 보정으로 자극과 같은 주어진 환경을 매우 일정하 게 유지시키는 노력이 필요하다.

\section{5. 결 론}

HS-SPME GC/MS를 이용하여 살아있는 C. japonicus 가 분비하는 페로몬을 분석하였고, 가장 최적화된 조 건을 설정하였다. HS-SPME를 살아있는 시료에 적용 할 경우, 각 시료의 생존이 가능한 범위 내에서 조건 을 최적화해야 한다. 용매로 추출해서 분석하는 일반 적인 SPME 법에 비하여 추출효율은 떨어질 수 있으 나, 현재 농촌진흥청에서 진행하고 있는 바이오그린21 사업 등과 같이 친환경적인 연구에 주목하고 있는 상 황에서 HS-SPME GC/MS는 친환경적이며 윤리적인 연구의 훌륭한 해결책이 될 수 있다.

\section{감사의 글}

“이 논문은 2011년도 정부(교육과학기술부)의 재원 으로 한국과학재단의 지원을 받아 수행된 연구임(No. 2012-0008123).”

\section{참고문헌}

1. J. Lisec, N. Schauer, J. Kopka, L. Willmitzer and A. R. Fernie, Nat. Protocols, 1(1), 387-396 (2006).
2. A. Kende, D. Portwood, A. Senior, M. Earll, E. Bolygo and M. Seymour, J. Chromatogr A, 1217(43), 67186723 (2010).

3. J. H. Kim, Anal. Sci. Technol, 24(2), 119-126 (2011).

4. M. S. Yu, S. B. Yang and N.-K. Ha, J. Envir. Sci., 19(12), 1447-1454 (2010).

5. M. N. Kayali-Sayadi, J. M. Bautista, D. Polo, amp, $x$, L. M. Ez and I. Salazar, J. Chromatogr B, 796(1), 5562 (2003).

6. W. Miekisch, P. Fuchs, S. Kamysek, C. Neumann and J. K. Schubert, Clin. Chim. Acta, 395(1-2), 32-37 (2008).

7. A. Mallouchos, M. Komaitis, A. Koutinas and M. Kanellaki, J. Agr. Food Chem., 50(13), 3840-3848 (2002).

8. K. Fiedler, E. Schtz and S. Geh, Int. J. Hyg. Envir. Heal, 204(2-3), 111-121 (2001).

9. C. A. Zini, F. Augusto, E. Christensen, E. B. Caramo and J. Pawliszyn, J. Agr. Food Chem, 50(25), 71997205 (2002).

10. B. D. Jackson and E. D. Morgan, Chemoecology, 4(3), 125-144 (1993).

11. Z. Liu, S. Yamane, Q. Wang and H. Yamamoto, J Ethol., 16(2), 57-65 (1998).

12. N. Fujiwara-Tsujii, N. Yamagata, T. Takeda, M. Mizunami and R. Yamaoka, Zool Sci., 23(4), 353-358 (2006).

13. U. Haak, B. Hlldobler, H. J. Bestmann and F. Kern, Chemoecology, 7(2), 85-93 (1996).

14. T. H. Jones, D. A. Clark, A. A. Edwards, D. W. Davidson, T. F. Spande and R. R. Snelling, J. Chem. Ecol., 30(8), 1479-1492 (2004).

15. G. Janssens, Anal. Chim. Acta, 95(2), 153-159 (1977).

16. R. B. Josens, W. M. Farina and F. Roces, J. Insect. Physiol., 44(7-8), 579-585 (1998). 